\title{
Cognitivism about Emotion and the Alleged Hyperopacity of Emotional Content
}

\author{
Uriah Kriegel \\ Forthcoming in Philosophical Studies
}

\section{Introduction/Abstract}

According to cognitivism about emotion, (all) emotions are reducible to some (combinations of) non-emotional states. In one version, they are reducible entirely to cognitive states, such as beliefs or judgments (Solomon 1976, Nussbaum 2001); in another, they are reducible to combinations of cognitive and conative states, such as desire or intention (Marks 1982, Gordon 1987). Cognitivism is plausibly regarded as the orthodoxy in the philosophy of emotion since the 1980s. In a recent paper, however, Montague (2009) develops a powerful argument against cognitivism. Here I argue that the argument nonetheless fails.

\section{Montague's Argument}

Suppose I apply for a grant for which only one applicant can be successful. My application is unsuccessful, and I am sad that they gave the grant to someone else. But - good news! - it turns out that the person who got the grant is none other than my best friend and favorite philosopher Jimmy. I am happy they gave it to him. I am happy about this even after learning that we were the only two applicants - though I am still sad that I did not get the grant. Montague's claim is that, when we examine closely the intentional structure of this episode, we realize that being happy that Jimmy succeeded is irreducible to believing that Jimmy succeeded and/or to desiring that Jimmy succeed. 
As far as desire is concerned, one can be happy that Jimmy succeeded without feeling any motivational pull toward that state of affairs (which already obtains anyway). But desire is inherently motivational - if a mental state does not motivate, it is ipso facto not a desire. So being happy that Jimmy succeeded does not involve as component desiring that Jimmy succeed. The trickier question is whether the happiness state might be grounded in some judgment or belief. Montague argues, however, that belief content is too coarse-grained to capture the content of emotion.

We can appreciate this by noting an asymmetry between belief and emotion. It is well known that belief contexts are opaque, so the following is invalid:

1) I believe (judge) that Jimmy succeeded;

2) Jimmy's success = my failure; therefore,

3) I believe (judge) that I failed.

If I am unaware that Jimmy's success just is my failure, I might not believe that I failed, even though I believe that Jimmy succeeded. So belief contexts are opaque. However, the following appears valid:

1) I believe (judge) that Jimmy succeeded;

2) I am fully aware that Jimmy's success = my failure; therefore,

3) I believe (judge) that I failed.

That is, I can perfectly rationally believe that Jimmy succeeded while disbelieving that I failed, but only if I am unaware that Jimmy's success just is my failure. We may signal this by saying that belief contexts are opaque but not hyperopaque. A context is hyperopaque if it does not support inferences of the sort just presented. Belief contexts do support such inferences, so they are not hyperopaque.

Emotion contexts, by contrast, are not only opaque but also hyperopaque. To be sure, the following is invalid:

1) I am happy that Jimmy succeeded; 
2) Jimmy's success = my failure; therefore,

3) I am happy that I failed.

But so is the following:

1) I am happy that Jimmy succeeded;

2) I am fully aware that Jimmy's success = my failure; therefore,

3) I am happy that I failed.

That is, full awareness of the identity does not void the rationality of being happy about Jimmy's success while remaining sad about my failure.

Since the content of happiness states is more fine-grained than that of beliefs, happiness is irreducible to belief (or judgment): the former is hyperopaque, the latter merely opaque. We may thus summarize Montague's argument as follows:

1) (some) emotions are hyperopaque and not inherently motivational;

2) (no) beliefs are hyperopaque;

3) (all) desires are inherently motivational; therefore,

4) (some) emotions are irreducible to beliefs and desires.

\section{Response}

My response to Montague's argument has two parts. The first has to do with a hidden conative component in happiness, different from desire; it addresses Premise 3 in Montague's argument as just reconstructed. The second part has to do with a distinction regarding the proper objects of happiness; it addresses Premise 2 in the reconstructed argument.

First, it is true that being happy or sad about events that have already occurred (such as the grant application outcome) does not involve desire. We generally do not have desires about the past, at least not if we believe it is unalterable - precisely because desire is inherently motivating. Accordingly, being happy about Jimmy's success does not involve desiring it. However, there is likely in 
our psychological repertoire an analogue of desire that is not inherently motivating. Arguably, that is precisely what wish is. Suppose I favor the end of world hunger, but am too spiritless to have any credence in my ability to contribute to the end of world hunger, and consequently experience no motivation toward trying to effect the end of world hunger. In that scenario - which appears perfectly psychologically possible - we might not say that I desire the end of world hunger; but we would say that I wish for the end of world hunger. Relatedly, at least as far as folk-psychological ascriptions are concerned, we seem willing to ascribe wishes - even rational wishes - regarding the unalterable. First, folk psychology allows for wishes regarding what is nomologically impossible, such as immortality or the ability to fly. Second, folk psychology allows for wishes regarding the past: 'Jane wishes the Armenian genocide had not occurred,' 'Joe wishes he was born in the sixties.' It is possible, of course, that folk psychology is simply wrong on this, but it is hard to imagine that there is no non-inherently-motivating desire-analogue in our psychological repertoire. I call this analogue 'wish,' with the thought that that is how the folkpsychological concept of a wish works; but if it is not how it works, we may use 'wish' in a technical way to denote the relevant analogue.

The point is that, for all Montague has argued, my sadness about my failure to get the grant may imply that I wish I had gotten it in this potentially technical sense - even though it does not imply that I desire I had gotten it. Likewise, my happiness about Jimmy's success at getting the grant involves the wish that he had gotten it. ${ }^{1}$ Being happy that $p$ involves as component wishing that $p$, or whatever the noninherently-motivating desire-analogue regarding $p$ is.

So much for the first part of my response. As for the second part, note that we can be happy about two sorts of things: facts and events. I can be happy (about the fact) that I strolled in the park or I can be happy about the (event of) my stroll in the park. Thus happiness takes both facts and events as intentional objects. ${ }^{2}$ It is natural to use the locution 'happy that' for the former and 'happy about' for the latter: 'I am happy that I strolled in the park' reports fact-happiness, 'I am happy about my stroll in the park' reports event-happiness. 
This is important, because it is highly plausible that facts and events individuate very differently (see Vendler 1967, Bennett 1988). For example, the fact that I strolled in the park and the fact that I strolled in the park slowly are two different facts: the latter is a much more specific, more determinate fact. By contrast, (the event of) my stroll in the park and (the event of) my slow stroll in the park are one and the same event: it is the same stroll, just more fully described in one case.

This matters for the evaluation of such inferences as used in Montague's argument. Consider again the third inference: 1) I am happy that Jimmy succeeded; 2) Jimmy's success = my failure; therefore, 3) I am happy that I failed. The first premise uses 'happy that' talk, which suggests that what is at stake is fact-happiness rather than event-happiness. Consistency would require us, then, to interpret Premise 2 as concerned with facts rather than events. But given the fine-grained individuation of facts, the fact that Jimmy succeeded is not identical to the fact that I failed (not any more than the fact that I strolled in the park is identical to the fact that I strolled in the park slowly). If so, Premise 2 is simply false. This provides us with a diagnosis of why the conclusion is false that does not assume the inference itself is invalid. The inference itself is perfectly valid but leads to a false conclusion due to a false premise.

More crucially for our present purposes, the same diagnosis applies to the fourth inference, which was used to argue for the hyperopacity of happiness. The second premise in this inference is 'I am fully aware that Jimmy's success = my failure.' Since 'fully aware' is a success verb, this premise cannot be true given that the fact of Jimmy's success $\neq$ the fact of my failure. So again we have an alternative diagnosis of the conclusion's falsity, one that does not involve asserting the invalidity of the inference.

To make the case that such inferences are indeed invalid, then, Montague must construe the second premises in the third and fourth argument schema as concerned with events, not facts. The event of Jimmy's success at getting the grant is indeed identical to the event of my failure to get the grant. But this forces us to 
interpret the rest of the reasoning as concerning events as well. The third inference now looks a tad different:

1) I am happy about the event of Jimmy's success at getting the grant;

2) Jimmy's success at getting the grant = my failure to get the grant; therefore,

3) I am happy about the event of my failing to get the grant.

This is indeed invalid, and demonstrates the opacity of emotion contexts. What about their alleged hyperopacity? Consider:

1) I am happy about the event of Jimmy's success at getting the grant;

2) I am fully aware that Jimmy's success at getting the grant = my failure to get the grant; therefore,

3) I am happy about the event of my failing to get the grant.

For emotion contexts to be hyperopaque, this argument would have to seem intuitively invalid. That is, the two premises would have to seem intuitively true and the conclusion intuitively false. But it is far from clear that the first premise is intuitively true. Intuitively, it is obviously the case that I am happy that Jimmy succeeded in getting the grant; but it is far less clear that I am happy about the event of his getting the grant. About the event, it would be reasonable for me rather to be ambivalent, not simply happy. For I am happy about one aspect of the event and sad about another (with the relevant event-aspects constituting different facts). To be at once happy and sad about the event itself, as a whole, would be reasonable only if I did not fully grasp that this is one and the same event. Yet that is precisely what is ruled out by the second premise. If I am both happy and sad about the event as a whole, and not about its two different aspects (hence about the two corresponding facts), then I am not really fully aware that Jimmy's success is my failure, as the second premise asserts. I must be somehow confused about that, or have a confused or indistinct awareness of that; otherwise I would be ambivalent about the event itself. Given the truth of the second premise, then, and given that presumably (or indeed by stipulation) all things considered I would rather I got the grant and not my friend, it is entirely unreasonable for me to be simply happy about the event of 
my friend getting the grant. For that would constitute happiness about my not getting the event. It thus seems inaccurate to describe me as happy about the event, as opposed to being ambivalent about it.

The upshot is that, unlike the original fourth inference, which clearly involved intuitively true premises and an intuitively false conclusion, the present inference does not clearly involve intuitively true premises. Accordingly, it is dialectically weak as a demonstration of an alleged hyperopacity of emotion contexts. What Montague's argument would need to go through is an inference in which there is a clear-cut intuition of true premises and a clear-cut intuition of a false conclusion. That would demonstrate the invalidity of the inference, and thence the hyperopacity of emotion contexts. It may turn out that such an inference could be devised, but for all Montague has shown, it may also turn out that it could not.

In summary, the inferences exploited in Montague's argument are ambiguous as between fact-happiness and event-happiness. Interpreted consistently as concerning fact-happiness, they support neither the opacity nor the hyperopacity of emotion contexts, as they involve a false premise. Interpreted consistently as concerning event-happiness, they support the opacity of emotion contexts but not quite their hyperopacity. Meanwhile, although (some) emotional states are not inherently motivational, so are states such as wish (at least as that concept seems to work in folk psychology). Therefore, a cognitivist reduction of emotion to combinations of belief and wishes is still viable. ${ }^{3}$

\section{References}

- Bennett, J. 1988. Events and their Names. Oxford: Oxford University Press.

- Gordon, R. 1987. The Structure of Emotion. Cambridge: Cambridge University Press.

- Marks, J. 1982. 'A Theory of Emotion.' Philosophical Studies 42: 227-242. 
- Montague, M. 2009. 'The Logic, Intentionality, and Phenomenology of Emotion.' Philosophical Studies 145: 171-192.

- Nussbaum, M. 2001. Upheavals of Thought: The Intelligence of Emotions. Cambridge: Cambridge University Press.

- Solomon, R. 1976. The Passions. New York: Doubleday.

- Vendler, Z. 1967. 'Facts and Events.' In his Linguistics in Philosophy. Ithaca NY: Cornell University Press.

${ }^{1}$ Such fulfilled wishes (wishes for what had in fact taken place) are much harder to notice introspectively than frustrated wishes (wishes about what had not taken place), but arguably they are there all the same.

2 This distinction pertains to what we may call 'transitive happiness,' the kind of happiness reported by a transitive verb. There is also what we might call 'intransitive happiness,' reported by the corresponding intransitive verb. It is an open question what the relationship between the two might be. One view is that 'S is happy' just means 'S is happy about S's life/existence.' This would analyze intransitive happiness in terms of transitive happiness. Another view, however, would reject any such analysis.

${ }^{3}$ For useful comments on a previous draft, I am grateful to an anonymous referee for Philosophical Studies. Work on this paper was supported by the French National Research Agency's grants ANR-10LABX-0087 IEC and ANR-10-IDEX-0001-02 PSL*. 